\title{
High risk of coagulopathy among Type-2 Diabetes Mellitus clients at a municipal hospital in Ghana
}

\author{
Richard K.D. Ephraim ${ }^{1}$, Yaw A. Awuku ${ }^{2}$, Patrick Adu ${ }^{1}$, Lord T.W. Ampomah ${ }^{1}$, Prince Adoba ${ }^{3}$, \\ Solomon Panford ${ }^{1}$, Jerry P.K Ninnoni ${ }^{4}$ and Hope Agbodzakey
}

Ghana Med J 2017; 51(3): 101-107 DOI: http://dx.doi.org/10.4314/gmj.v51i3.2

\begin{abstract}
${ }^{1}$ Department of Medical Laboratory Science, School of Allied Health Sciences, University of Cape Coast, Cape Coast ${ }^{2}$ Department of Internal Medicine and Therapeutics, University of Cape Coast, Cape Coast ${ }^{3}$ Department of Molecular Medicine, School of Medical Sciences, College of Health Sciences, Kwame Nkrumah University of Science and Technology, Kumasi, Ghana, ${ }^{4}$ Department of Mental Health, School of Nursing, University of Cape Coast, Cape Coast, Ghana
\end{abstract}

Corresponding author: Dr. Richard K.D. Ephraim

E-mail: rephraim@ucc.edu.gh

Conflict of interest: None declared

\section{SUMMARY}

Background: Persistent hyperglycaemia in diabetes mellitus causes coagulopathies due to glycation of haemoglobin, prothrombin, fibrinogen and other proteins involved in the clotting mechanism. Shortened activated partial thromboplastin time (APTT) and prothrombin time (PT) reflect hypercoagulable state, which is associated with an increased thrombotic risk and adverse cardiovascular effects. This study assessed the coagulation profile of type 2 diabetes mellitus (T2DM) clients at a municipal hospital in Ghana.

Methods: A hospital-based case-control study was conducted from January to April 2015 at the Agona Swedru Municipal Hospital. Sixty (60) persons with T2DM and 40 without were recruited and screened using appropriate protocols. Blood samples were collected for coagulation and biochemical tests. Demographic and clinical information were collected using pre-tested questionnaire. Data was analyzed with GraphPad Prism version 5.

Results: APTT and PT were significantly shorter among patients with T2DM compared to those without (20.88 \pm 5.19 v $31.23 \pm 5.41, P=0.0001$; and $11.03 \pm 2.06 \mathrm{sec}$ v $14.46 \pm 1.86, P=0.0001$ respectively). INR was decreased among patients with T2DM compared to those without $(0.83 \pm 0.18 \mathrm{v} 1.13 \pm 0.17, P=0.0001)$. No significant difference was found in platelet count between T2DM and non-diabetics $\left(179.85 \pm 66.15 \times 10^{3} / \mathrm{mm}^{3} \mathrm{v} 168.55 \pm 35.77 \times 10^{3}\right.$ $/ \mathrm{mm}^{3}, P=0.326$ ). Serum magnesium was lower among the T2DM patients compared to the non-diabetics, while serum ionized calcium was significantly higher among the T2DM patients $(\mathrm{P}<0.05)$.

Conclusion: Clients with T2DM may have a high coagulation risk evidenced by shortened APTT, PT and a high ionized calcium compared with controls.

Funding: Study was funded by Lord Ampomah and Solomon Panford

Keywords: Type 2 Diabetes Mellitus, coagulation, prothrombin time, activated partial thromboplastin time, ionized calcium

\section{INTRODUCTION}

Diabetes mellitus (DM) is a group of metabolic diseases characterized by increased blood glucose, which results primarily from defects in insulin secretion, insulin action, or both and symptoms include polyuria, polydipsia and polyphagia. ${ }^{1}$ Prevalence of DM worldwide is $8.5 \%$ with $6.3 \%$ prevalence in Ghana. ${ }^{2}$ The prevalence in Ghana has recently been estimated to be $3 \%$ of the country's general populace. $^{3}$
Metabolic disturbances that commonly occur in patients with type 2 diabetes are atherogenic dyslipidaemia, hypertension, glucose intolerance, and a prothrombotic state. ${ }^{4,5}$ This prothrombotic state is a more recently recognized component of the metabolic syndrome; people with metabolic syndrome exhibit a pattern of coagulation factors that promote thrombosis or retard thrombolysis. ${ }^{5,6}$ 


\section{Original Article}

The underlying mechanisms for increased thrombosis risk in diabetes are complex and involve multiple pathways.

Subjects with diabetes have premature atherosclerosis and more extensive vascular disease, predisposing them to plaque rupture and thrombus formation. In addition, these individuals have increased thrombotic tendency due to platelet hyper-reactivity and increased activation of prothrombotic coagulation factors coupled with decreased fibrinolysis.

The prothrombotic state is characterized by increased fibrinogen levels ${ }^{7}$, increased plasminogen activator inhibitor (PAI)- $1^{8}$, and different abnormalities in platelet function. ${ }^{6}$ Studies have reported contrasting coagulation profiles among diabetes patients. Acang and Jalil ${ }^{9}$ reported shorter prothrombin times (PTs) and activated partial thromboplastin times (APTTs) in patients with diabetes. Conversely, Collier et al ${ }^{10}$ found normal PTs in patients with type 2 diabetes. Erem et $a l^{11}$ reported normal PTs and APTTs in diabetes.

Although sub-Saharan Africa has the highest burden of diabetes, many studies have not been done in this region to explore the impact of diabetes mellitus on coagulation profile. We therefore sought to assess the coagulation profile of persons with type 2 Diabetes Mellitus (T2DM) in a district hospital in Ghana.

\section{METHODS}

\section{Study Design/ Study Site}

This was a hospital-based case control study conducted from January to April 2015 at the Agona Swedru Municipal Hospital (ASMH) in the Central Region of Ghana. ASMH is located in Agona West District with a total projected population of 403,943 . The hospital is the largest health facility in the district and serves as the main referral facility in the district and its neighbouring villages. As per the records of the OPD unit, the total number of diabetes patient who visit the hospital is 651 per year; 500 of these are T2DM patients.

\section{Study Population}

A total of 100 participants comprising 60 T2DM patients and 40 non-Diabetics attending the out-patient department of ASMH in Agona Swedru were recruited for the study. Persons with type 1 Diabetes Mellitus and controls with known liver disease were excluded from the study.

\section{Ethical Consideration}

The study had approval from the University of Cape Coast Institutional Review Board (UCCIRB) and the hospital authorities.
A written consent was sought from participants after a thorough explanation of the study protocols. Results and records were strictly kept confidential.

\section{Administration of Questionnaire}

A well-structured questionnaire was used to obtain information on demographic variables such as age, sex, occupation, gender; and clinical history of each participant

\section{Blood Pressure Measurement}

Trained personnel measured the blood pressure using a mercury sphygmomanometer and a stethoscope. All measurements were in accordance with recommendations of the American Heart Association. ${ }^{12}$ Hypertension was graded as normal when the systolic blood pressure (SBP) was $<120 \mathrm{~mm} \mathrm{Hg}$ and diastolic blood pressure (DBP) was $<80 \mathrm{~mm} \mathrm{Hg} .^{13}$

\section{Anthropometrics}

The height (to the nearest metre) using a wall-mounted graduated ruler and weight (to the nearest $0.1 \mathrm{~kg}$ ) in light clothing, with a weighing balance (Seca, Hamburg, Deutschland) were measured. The body mass index (BMI) was then calculated as the ratio of the weight $(\mathrm{kg})$ and the square of the height $\left(\mathrm{m}^{2}\right)$. BMI was categorized as: $<18.5$ (underweight); 18.5 to 24.5 (normal weight); 25 to 29.5 (overweight); and $\geq 30$ (obese).

The hip circumference at the widest portion of the buttocks and waist circumference midway between the inferior margin of the last palpable rib and the suprailiac crest (both to the nearest $0.1 \mathrm{~cm}$ ) were also measured using a measuring tape. The waist-hip ratio was calculated from the waist circumference/ hip circumference.

\section{Blood sample collection}

From each consented participant, $10 \mathrm{ml}$ of venous blood (fasting) was collected of which $5 \mathrm{ml}$ was put into fluoride oxalate tube, $1.4 \mathrm{ml}$ into a tube containing EDTA and $3.6 \mathrm{ml}$ into a plastic buffered tri-sodium citrate tube containing $380 \mu \mathrm{l}$ of $3.2 \%$ buffered tri-sodium citrate. The sample in $3.2 \%$ buffered tri-sodium citrate tube and fluoride oxalate tube were centrifuged at $1500 \mathrm{rpm}$ for 15 minutes and the plasma separated for PT/APTT and plasma glucose measurements respectively.

\section{Biochemical Tests}

Fasting plasma glucose was estimated using the glucose oxidase/peroxidase method. ${ }^{14}$ Serum albumin, total calcium and magnesium were estimated using an autoanalyser (Mindray, China). Ionized calcium (Cal-I) was then calculated using the formula; Cal-I $\mathrm{mmol} / \mathrm{L}=0.25$ $\mathrm{x}[0.9+(0.55 \times \mathrm{Cal}-\mathrm{T} \mathrm{mg} / \mathrm{dL})-(0.3 \times$ albumin $\mathrm{g} / \mathrm{dL})]{ }^{15}$ 


\section{APTT, PT, and platelet estimation}

Platelet count was estimated using Sysmex Haematology Analyser (Sysmex XT-2000i, Kobo, Japan). Prothrombin time and activated partial thromboplastin time were estimated on venous blood anticoagulated with sodium citrate. INR was calculated using the formula: $\mathrm{INR}=(\mathrm{PT} \text { patient/GMNPT })^{\mathrm{IS}}$, where GMNPT is geometric mean normal prothrombin time from 20 normal donors and ISI is international sensitivity index.

\section{Statistical Analysis}

Data was entered into Microsoft Excel and statistical analysis was carried out using Statistical Package for Social Sciences (SPSS) version 17.0 for Microsoft Windows, $13^{\text {th }}$ students' edition. Continuous variables were reported using mean and standard deviation and Chi square model used to analyze categorical variables. $P<0.05$ was considered statistically significant

\section{RESULTS}

Table 1 Demographic, anthropometric, clinical characteristics and biochemical profile of persons with T2DM (Cases) and non-diabetics (Control)

\begin{tabular}{|c|c|c|c|}
\hline Variable & Subjects & Control & p-value \\
\hline & $(\mathrm{n}=60)$ & $(\mathrm{n}=40)$ & \\
\hline Age (years) & $55.98 \pm 14.05$ & $34.13 \pm 7.67$ & $<0.0001$ \\
\hline Gender & & & 0.803 \\
\hline Male & $24(40.0)$ & $17(42.5)$ & \\
\hline Female & $36(60.0)$ & $23(57.5)$ & \\
\hline Occupation & & & $<0.0001$ \\
\hline Unemployed & $7(11.7)$ & $2(5.0)$ & \\
\hline Informal & $41(68.3)$ & $14(35.0)$ & \\
\hline Formal & $12(20.0)$ & $24(60.0)$ & \\
\hline$S B P(m m H g)$ & $146.28 \pm 31.91$ & $118.75 \pm 13.99$ & $<0.0001$ \\
\hline$D B P(m m H g)$ & $80.28 \pm 20.36$ & $76.50 \pm 9.21$ & 0.274 \\
\hline$F B G(\mathrm{mmol} / \mathrm{L})$ & $11.84 \pm 6.25$ & $4.55 \pm 0.41$ & $<0.0001$ \\
\hline WHR $(\mathrm{cm})$ & $0.94 \pm 0.10$ & $0.83 \pm 0.10$ & $<0.0001$ \\
\hline$B M I\left(K g / m^{2}\right)$ & $21.48 \pm 4.41$ & $20.67 \pm 4.60$ & 0.381 \\
\hline \multicolumn{4}{|c|}{ Coagulation Profile } \\
\hline PLT $\times 10^{3} / \mathrm{mm}^{3}$ & $179.85 \pm 66.15$ & $168.55 \pm 35.77$ & 0.326 \\
\hline APTT & $20.88 \pm 5.19$ & $31.23 \pm 5.41$ & $<0.0001$ \\
\hline PT & $11.03 \pm 2.06$ & $14.46 \pm 1.86$ & $<0.0001$ \\
\hline INR & $0.83 \pm 0.18$ & $1.13 \pm 0.17$ & $<0.0001$ \\
\hline Albumin, $g / L$ & $34.96 \pm 3.89$ & $37.73 \pm 2.88$ & $<0.0001$ \\
\hline $\begin{array}{l}\text { Magnesium, } \\
\mathrm{mmol} / \mathrm{L}\end{array}$ & $0.75 \pm 0.12$ & $0.91 \pm 0.16$ & $<0.0001$ \\
\hline $\begin{array}{l}\text { Calcium-Total, } \\
\text { mmol/L }\end{array}$ & $2.50 \pm 0.28$ & $2.42 \pm 0.20$ & 0.110 \\
\hline $\begin{array}{l}\text { Calcium- } \\
\text { ionized, } \mathrm{mmol} / \mathrm{L}\end{array}$ & $1.36 \pm 0.22$ & $1.27 \pm 0.11$ & 0.024 \\
\hline
\end{tabular}

SBP $=$ Systolic Blood Pressure, DBP $=$ Diastolic Blood Pressure, FBG $=$ Fasting Blood Glucose PLT=Platelet, WHR=Waist Hip Ratio, BMI $=$ Body Mass Index, APTT=Activated Partial Thromboplastin, PT=Prothrombin Time
The mean age of the type 2 Diabetes Mellitus patients was $55.9 \pm 14.1$ years, with majority of them in their sixth decade of life.

There was no significant difference in the platelet count and total calcium level of the type 2 diabetes patients and the non-diabetics.

Table 2 Demographics and clinical characteristics of persons with T2DM stratified by gender

\begin{tabular}{|l|l|l|l|}
\hline Variable & Male & Female & $\begin{array}{l}\text { p-- } \\
\text { value }\end{array}$ \\
\hline Age (years) & $59.42 \pm 13.67$ & $53.69 \pm 14.03$ & 0.123 \\
\hline Occupation & & & 0.318 \\
\hline Unemployed & $3(42.9)$ & $4(57.1)$ & \\
\hline Informal & $14(34.1)$ & $27(65.9)$ & \\
\hline Formal & $7(58.3)$ & $5(41.7)$ & \\
\hline $\begin{array}{l}\text { Duration of } \\
\text { drug } \\
\text { (years) }\end{array}$ & $4.46 \pm 3.09$ & $3.89 \pm 2.31$ & 0.579 \\
\hline $\begin{array}{l}\text { Clinical Char- } \\
\text { acteristics }\end{array}$ & & & \\
\hline Polyuria & & & 0.785 \\
\hline Yes & $20(40.8)$ & $29(59.2)$ & \\
\hline No & $4(36.4)$ & $7(63.6)$ & \\
\hline Weight Loss & & & 0.645 \\
\hline Yes & $16(38.1)$ & $26(61.9)$ & \\
\hline No & $8(44.4)$ & $10(55.6)$ & \\
\hline Blurred Vision & & & 0.598 \\
\hline Yes & $20(41.7)$ & $28(58.3)$ & \\
\hline No & $4(33.3)$ & $8(66.7)$ & \\
\hline $\begin{array}{l}\text { Secondary } \\
\text { Conditions }\end{array}$ & & & \\
\hline Yes & $16(37.2)$ & $27(62.8)$ & \\
\hline No & $8(47.1)$ & $9(52.9)$ & \\
\hline
\end{tabular}

However, PT, APTT and INR were significantly decreased among persons with type 2 diabetes compared to non-diabetics. Serum albumin and magnesium were significantly lower among the type 2 diabetes patients compared to the non-diabetics; while serum ionized calcium was significantly higher among the type 2 patients (Table 1).

Table 2 presents the demographics and clinical characteristics of the diabetic patients stratified by gender. Informal occupation and unemployment were more in females than in males $(65.9 \% \mathrm{v} 34.1 \%$; and $57.1 \% \mathrm{v}$ $42.9 \%$ respectively).

There was no significant difference in duration of drug use among males and females $(P=0.579)$. Polyuria (59.2), weight loss $(61.9 \%)$ impaired wound healing $(66.7 \%)$, blurred vision $(58.3 \%)$ and presence of sec- 


\section{Original Article}

ondary conditions $(62.8 \%)$ were higher in females than in males.

Table 3 shows coagulation profile and anthropometric measures of diabetics on therapy (Cases) stratified by gender. Apart from PT and FBG, there was no significant difference in the coagulation and biochemical profile of the type 2 diabetes patients with respect to gender. WHR and BMI were associated with gender $(\mathrm{P}<0.05)$.

Table 3 Biochemical profile and anthropometric measures of persons with T2DM stratified by gender

\begin{tabular}{|l|l|l|l|}
\hline & Male & Female & P-value \\
\hline & $(\mathrm{n}=24)$ & $(\mathrm{n}=36)$ & \\
\hline Coagulation Profile & & & \\
\hline PLT $10^{3} / \mathrm{mm}^{3}$ & $187.96 \pm 73.88$ & $174.44 \pm 60.95$ & 0.443 \\
\hline APTT & $21.67 \pm 6.01$ & $20.36 \pm 4.59$ & 0.345 \\
\hline PT & $11.54 \pm 2.35$ & $10.69 \pm 1.81$ & 0.119 \\
\hline INR & $0.88 \pm 0.20$ & $0.81 \pm 0.16$ & 0.160 \\
\hline $\begin{array}{l}\text { Coagulation Profile } \\
\text { n (\%) }\end{array}$ & & & \\
\hline PLT & & & 0.280 \\
\hline$<150$ & $6(30.0)$ & $14(70.0)$ & \\
\hline $150-450$ & $17(43.6)$ & $22(56.4)$ & \\
\hline$>450$ & $1(100)$ & $0(0.0)$ & \\
\hline APTT & & & 0.383 \\
\hline$<25$ & $17(37.0)$ & $29(63.0)$ & \\
\hline $25-43$ & $7(50.0)$ & $7(50.0)$ & \\
\hline PT & & & $\mathbf{0 . 0 0 7}$ \\
\hline$<10$ & $3(20.0)$ & $12(80.0)$ & \\
\hline $10-14$ & $16(40.0)$ & $24(60.0)$ & \\
\hline$>14$ & $5(100)$ & $0(0.0)$ & \\
\hline INR & $0.88 \pm 0.20$ & $0.81 \pm 0.16$ & 0.160 \\
\hline Albumin, g/L & $34.65 \pm 4.25$ & $35.18 \pm 3.68$ & 0.621 \\
\hline Magnesium, mmol/L & $0.73 \pm 0.11$ & $0.76 \pm 0.12$ & 0.417 \\
\hline $\begin{array}{l}\text { Calcium-Total, } \\
\text { mmol/L }\end{array}$ & $2.49 \pm 0.31$ & $2.51 \pm 0.26$ & 0.802 \\
\hline $\begin{array}{l}\text { Calcium-ionized, } \\
\text { mmol/L }\end{array}$ & $1.39 \pm 0.31$ & $1.34 \pm 0.14$ & 0.435 \\
\hline SBP (mmHg) & $146.67 \pm 34.60$ & $146.03 \pm 30.49$ & 0.940 \\
\hline DBP (mmHg) & $83.04 \pm 27.37$ & $78.44 \pm 14.07$ & 0.396 \\
\hline FBG (mmol/L) & $14.21 \pm 7.83$ & $10.27 \pm 4.39$ & $\mathbf{0 . 0 1 5}$ \\
\hline WHR (cm) & $0.93 \pm 0.06$ & $0.94 \pm 0.11$ & 0.900 \\
\hline BMI (Kg/m2) & $19.60 \pm 3.99$ & $22.73 \pm 4.27$ & $\mathbf{0 . 0 0 6}$ \\
\hline & & & \\
\hline & & & \\
\hline
\end{tabular}

We also used multivariate logistic regression analysis to investigate factors that could predict coagulation abnormality in T2DM patients (Table 4).

Our study showed that age, waist-hip ratio (WHR), body mass index (BMI), duration of drug use, and the presence of secondary conditions do not significantly predict low PT, APTT or platelet count.

\section{DISCUSSION}

Prothrombotic state is a more recently recognized component of the metabolic syndrome. People with the metabolic syndrome, as in T2DM, exhibit a pattern of co- agulation factors that promote thrombosis or retard thrombolysis. ${ }^{5}$

This study sought to measure clotting profile and platelet count in patients with T2DM. Our findings showed significantly shorter APTT and PT, with concurrent significantly higher ionized calcium among patients with T2DM compared to the non-Diabetics. These findings demonstrate an increased predisposition to thrombotic events in T2DM patients compared to nonDiabetic controls.

Our findings are consistent with other previously published reports that found shortened APTT and PT in diabetes patients compared to non-diabetic controls. ${ }^{9,16}$ In an epidemiological study that investigated the association between plasma glucose levels and APTT in type 2 diabetes mellitus patients, Lippi et al., ${ }^{16}$ also found shortened APTT in diabetes patients. However, a simiar case-control study by Madan et al., ${ }^{17}$ did not find any significant difference in APTT among type 2 diabetics and healthy controls. The Medan et al., study however recruited a relatively lower sample size in the control group (30 vs 40 in this study) which might have fccounted for this variance in addition to the differences in the population demographics. Similarly, PT and INR were shorter among the type 2 Diabetics compared to the controls.

This study also corroborates the shorter APTT recorded by Acang and Jalil ${ }^{9}$ but is inconsistent with the findings of Zhao et al., ${ }^{18}$ who obtained insignificant shortened T value among patients with type 2 diabetes in a casecontrol study in Zhejiang University in China. Madan et al., ${ }^{17}$ also did not find any difference in PT among type 2 Diabetics. The differences in coagulation test results bsserved could be due to differences in sample size used, race and geographical locations.

onized calcium is a critical component of the coagulation cascade in man and therefore any derangement in ts levels may have adverse consequences on the coagulation profile. Previous studies have reported abnormal calcium levels among patients with diabetes. ${ }^{19-21}$ This is supported by the significantly higher serum ionized calcium among type 2 diabetes patients in our study.

Variation with regard to calcium and $\mathrm{Na}^{+} / \mathrm{K}^{+}$-ATPase activities and abnormal hormonal regulation of intracellular calcium has been implicated in the abnormal calcium levels reported in T2DM. ${ }^{22}$ As ionized calcium represent the biologically active form of calcium readily available for physiological functions, its significant increase in diabetes patients could predispose them to thrombotic events. 
Table 4 Regression analyses of factors associated with decrease in measures of coagulation abnormality

\begin{tabular}{|c|c|c|c|c|c|c|}
\hline \multirow[t]{2}{*}{ Parameter } & \multicolumn{2}{|l|}{ Platelets } & \multirow{2}{*}{$\begin{array}{l}\text { APTT } \\
\text { OR }(95 \% \text { CI }) \\
\end{array}$} & \multirow[b]{2}{*}{ P-value } & \multicolumn{2}{|l|}{ PT } \\
\hline & OR $(95 \%$ CI $)$ & P-value & & & OR (95\% CI) & P-value \\
\hline \multicolumn{7}{|l|}{ Gender } \\
\hline Male* & 1 & & 1 & & 1 & \\
\hline Female & $1.91(0.61-5.98)$ & 0.267 & $1.71(0.51-5.70)$ & 0.386 & $3.50(0.87-14.11)$ & 0.078 \\
\hline \multicolumn{7}{|l|}{ Age group } \\
\hline$<30^{*}$ & 1 & & 1 & & & \\
\hline $30-39$ & - & - & $0.50(0.02-11.08)$ & 0.661 & $0.2(-)$ & - \\
\hline $40-49$ & $0.08(0.00-2.05)$ & 0.128 & & & $1.50(0.09-25.39)$ & 0.779 \\
\hline $50-59$ & $0.18(0.01-2.32)$ & 0.187 & $1.42(0.11-18.60)$ & 0.791 & $0.42(0.03-5.85)$ & 0.519 \\
\hline $60-69$ & $0.50(0.04-7.10)$ & 0.609 & $2.50(0.15-42.80)$ & 0.527 & $2.00(0.14-28.42)$ & 0.609 \\
\hline$\geq 70$ & $0.42(0.03-6.06)$ & 0.522 & $1.33(0.09-20.71)$ & 0.837 & $2.00(0.01-4.72)$ & 0.318 \\
\hline \multicolumn{7}{|l|}{ WHR } \\
\hline Normal* & 1 & & 1 & & 1 & \\
\hline Overweight & $0.54(0.15-1.97)$ & 0.346 & $0.89(0.19-4.13)$ & 0.885 & $0.78(0.19-3.27)$ & 0.734 \\
\hline Obese & $2.57(0.56-11.72)$ & 0.224 & $0.30(0.06-1.63)$ & 0.164 & $2.32(0.47-11.55)$ & 0.303 \\
\hline \multicolumn{7}{|l|}{$B M I$} \\
\hline Underweight & $1.21(0.36-4.09)$ & 0.760 & $0.52(0.14-1.97)$ & 0.338 & $0.63(0.14-2.83)$ & 0.545 \\
\hline Normal* & 1 & & 1 & & 1 & \\
\hline Overweight & $0.63(0.14-2.88)$ & 0.554 & $1.30(0.22-7.61)$ & 0.768 & $2.25(0.54-9.37)$ & 0.267 \\
\hline Obese & $0.09(0.000)$ & - & 2.84 & - & $0.03(0.000)$ & - \\
\hline \multicolumn{7}{|l|}{$2^{o}$ Condition } \\
\hline Yes & $0.89(0.27-2.89)$ & 0.840 & $1.57(0.44-5.64)$ & 0.486 & $1.81(0.44-7.43)$ & 0.412 \\
\hline No* & 1 & & 1 & & 1 & \\
\hline
\end{tabular}

Platelet function in haemostasis may be affected by quality and/or quantity of the platelets. Vinik et al. ${ }^{23}$ observed functional anomalies in platelets in type 2 diabetes suggesting that any impact of diabetes on platelets may be qualitative but not quantitative. In line with this we found no significant difference in platelet count between diabetes and non-diabetes controls. This agrees with Madan et al., ${ }^{17}$ who also reported non-significant variation in platelet count between diabetes patients with or without complications and healthy controls.

In addition, the lower serum magnesium found among type 2 diabetes patients compared to non-diabetics is in line with the findings of Wälti et al., ${ }^{24}$ who demonstrated low magnesium status in type 2 Diabetics in the Zurich region of Switzerland.
Magnesium (Mg) depletion has an effect on glucose homeostasis and insulin sensitivity in diabetic patients ${ }^{25}$ as well as on the evolution of complications such as thrombosis and hypertension. ${ }^{25}$

Other studies have shown inhibitory effects of $\mathrm{Mg}$ on platelet function through various suggested mechanisms such as production of prostacyclin ${ }^{26}$ or altered inositol phosphate generation. ${ }^{27}$ Therefore our finding of significantly reduced $\mathrm{Mg}$ levels in T2DM supports studies from others who suggested that oral $\mathrm{Mg}$ supplementation may be beneficial in preventing the platelet hyperactivity associated with diabetes and its consequent coronary events. ${ }^{25-28}$ 
Previously, others have suggested that individuals with T2DM have increased thrombotic tendency due to platelet hyper-reactivity as well as increased activation of prothrombotic coagulation factors coupled with decreased fibrinolysis. $^{29}$

This is supported by the finding of decreased PT and APTT in our study together with the significantly reduced $\mathrm{Mg}$ levels in our diabetes subjects.

This thrombotic predisposition may be compounded by the significantly elevated ionized calcium (Factor IV) among the type 2 diabetes patients compared to the healthy controls. However, further studies that possibly employ animal models are recommended to ascertain exact pathophysiological role of ionized calcium in these patients.

Additionally, we recommend a similar study to be undertaken that will compare the coagulopathy in T2DM patients with poor glycaemic control and those with tightly controlled glycaemia to inform clinicians in the management of these patients. Our study is limited by the small sample size and inability to perform specific factor assays as well as platelet function assay.

\section{CONCLUSION}

A shorter APTT and PT were found among patients with T2DM compared to the non-Diabetics. There was no significant difference in platelet count between type 2 diabetic patients and non-diabetics, with serum ionized calcium being higher among the type 2 Diabetic patients. This indicates higher risk of thrombosis in T2DM patients. Coagulation profile must be considered as a routine test among diabetes patients during their scheduled clinic visit and anti-coagulation measures instituted appropriately.

\section{ACKNOWLEDGEMENTS}

The authors acknowledge the immense contributions of the patients and staff of the Agona West Municipal Hospital

\section{REFERENCES}

1. A.D.A., Diagnosis and classification of diabetes mellitus. Diabetes Care, 2006. 29 (Suppl 1): p. S43-8.

2. Amoah, A.G., S.K. Owusu, and S. Adjei, Diabetes in Ghana: a community based prevalence study in Greater Accra. Diabetes Res Clin Pract, 2002. 56(3): p. 197-205.

3. Saeed, B.I., et al., The effect of socio-economic predictors of chronic diseases in Ghana: results of a nationwide survey. Glob J Health Sci, 2013. 5(5): p. 115-23.
4. Reaven, G.M., Role of insulin resistance in human disease. Diabetes, 1988. 37: p. 1595-1607.

5. Grundy, S.M., Hypertriglyceridemia, a therogenic dyslipidemia, and the metabolic syndrome. Am J Cardiol, 1998. 81(4A): p. 18B-25B.

6. Nolan, R.D. and A.I. Vinik, Pathogenesis of platelet dysfunction in diabetes. In Diabetes Mellitus: A Fundamental and Clinical Text, ed. D. LeRoith, Olefsky, JM, Taylor, SI,. 1996: Philadelphia, Lippincott-Raven. p. 832-839.

7. Imperatore, G., et al., Plasma fibrinogen: a new factor of the metabolic syndrome. A populationbased study. Diabetes Care, 1998. 21(4): p. 649-54.

8. Byberg, L., et al., Plasminogen activator inhibitor-1 activity is independently related to both insulin sensitivity and serum triglycerides in 70-year-old men. Arterioscler Thromb Vasc Biol, 1998. 18(2): p. 258-64.

9. Acang, N. and F.D. Jalil, Hypercoagulation in diabetes mellitus. Southeast Asian J Trop Med Public Health, 1993. 24 Suppl 1: p. 263-6.

10. Collier, A., et al., Free radical activity and hemostatic factors in NIDDM patients with and without micoalbuminuria. Diabetes 1992. 41: p. 909-913.

11. Erem, C., et al., Coagulation and fibrinolysis parameters in type 2 diabetic patients with and without diabetic vascular complications. Med Princ Pract, 2005. 14: p. 22-30.

12. Kirkendall, W.M., et al., Recommendations for human blood pressure determination by sphygmomanometer. Circulation, 1967. 36: p. 980-988.

13. Chobanian, A.V., G.L. Bakris, and H.R. Black, The Seventh Report of the Joint National Committee on Preventions, detection, evaluation, and Treatment of High Blood Pressure. JAMA, 2003. 289: p. 560571.

14. Barham, D. and P. Trinder, An improved colour reagent for the determination of blood glucose by the oxidase system. Analyst, 1972. 97(1151): p. 142-145.

15. Ferreira-Junior, M., et al., Rational use of blood calcium determinations. Sao Paulo Med J, 2014. 132(4): p. 243-8.

16. Lippi, G., et al., Epidemiological association between fasting plasma glucose and shortened APTT. Clin Biochem, 2009. 42(1-2): p. 118-20.

17. Madan, R., et al., Coagulation profile in diabetes and its association with diabetic microvascular complications. J Assoc Physicians India, 2010. 58: p. 481-484.

18. Zhao, Y., J. Zhang, and J. Wu, Diabetes mellitus is associated with shortened activated partial thromboplastin time and increased fibrinogen values. PLoS One. 6(1): p. e16470. 
19. Sun, G., et al., Altered calcium homeostasis is correlated with abnormalities of fasting serum glucose, insulin resistance, and beta-cell function in the Newfoundland population. Diabetes, 2005. 54(11): p. 3336-9.

20. Yamaguchi, T., et al., Serum calcium is positively correlated with fasting plasma glucose and insulin resistance, independent of parathyroid hormone, in male patients with type 2 diabetes mellitus. Metabolism, 2011. 60(9): p. 1334-9.

21. Sorva, A. and R.S. Tilvis, Low serum ionized to total calcium ratio: association with geriatric diabetes mellitus and with other cardiovascular risk factors? Gerontology, 1990. 36(4): p. 212-6.

22. Levy, J., et al., Effects of food restriction and insulin treatment on $(\mathrm{Ca} 2++\mathrm{Mg} 2+)$-ATPase response to insulin in kidney basolateral membranes of noninsulin-dependent diabetic rats. Metabolism, 1990. 39(1): p. 25-33.

23. Vinik, A.I., et al., Platelet dysfunction in type 2 diabetes. Diabetes Care, 2001. 24(8): p. 1476-85.
24. Walti, M.K., et al., Measurement of magnesium absorption and retention in type 2 diabetic patients with the use of stable isotopes. Am J Clin Nutr, 2003. 78(3): p. 448-53.

25. Nadler, J.L., et al., Intracellular free magnesium deficiency plays a key role in increased platelet reactivity in type II diabetes mellitus. Diabetes Care, 1992. 15(7): p. 835-41.

26. Nadler, J.L., S. Goodson, and R.K. Rude, Evidence that prostacyclin mediates the vascular action of magnesium in humans. Hypertension, 1987. 9(4): p. 379-83.

27. Roth, BL. Modulation of phosphatidyl-inositol-4,5biphosphate hydrolysis in rat aorta by guanine nucleotide, calcium and magnesium. Life Sci, 1987. 41: p. 629-34.

28. Trip, M.D., et al., Platelet hyperactivity and prognosis in survivors of myocardial infarction. $N$ Engl J Med, 1990. 322(22): p. 1549-54.

29. Alzahrani, S.H. and R.A. Ajjan, Coagulation and fibrinolysis in diabetes. Diab Vasc Dis Res, 2010. 7(4): p. 260-73. 